\title{
Determining Concentrations of 2-Bromoallyl
}

\section{Alcohol and Dibromopropene in Ground Water \\ Using Quantitative Methods}

By Sandra Y. Panshin

U.S. GEOLOGICAL SURVEY

Open-File Report 97-43

NATIONAL WATER QUALITY ASSESSMENT PROGRAM

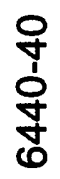

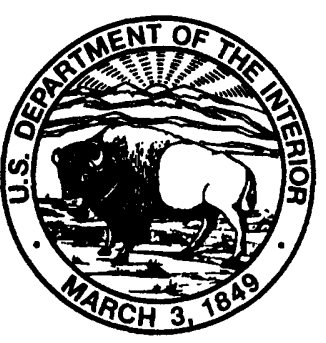




\title{
U.S. DEPARTMENT OF THE INTERIOR BRUCE BABBITT, Secretary
}

\author{
U.S. GEOLOGICAL SURVEY
}

Gordon P. Eaton, Director

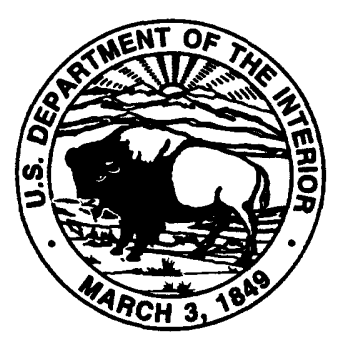

The use of firm, trade, and brand names in this report is for identification purposes only and does not constitute endorsement by the U.S. Geological Survey

For additional information write to:

District Chief

U.S. Geological Survey

Water Resources Division

Placer Hall

$6000 \mathrm{~J}$ Street

Sacramento, CA 95819-6129
Copies of this report can be purchased from:

U.S. Geological Survey

Branch of Information Services

Box 25286

Denver, CO 80225-0286 


\begin{tabular}{rccl}
\hline Multiply & By & To obtain \\
\hline meter (m) & 3.281 & foot \\
meter (m) & 1.094 & yard \\
liter (L) & 33.82 & ounce, fluid \\
liter (L) & 2.113 & pint \\
liter (L) & 1.057 & quart \\
liter (L) & 0.2642 & gallon \\
liter (L) & 61.02 & cubic inch \\
gram (g) & 0.03527 & ounce, avoirdupois \\
\hline
\end{tabular}

Temperature in degrees Celsius $\left({ }^{\circ} \mathrm{C}\right)$ may be converted to degrees Fahrenheit $\left({ }^{\circ} \mathrm{F}\right)$ as follows:

$$
{ }^{\circ} \mathrm{F}=\left(1.8 \times{ }^{\circ} \mathrm{C}\right)+32
$$

\section{Abbreviations}

BAA, 2-bromoallyl alcohol

DBCP, 1,2-dibromo-3-chloropropane

DBP, 2,3-dibromopropene

BCP, 2-bromo-3-chloropropene

$\mathrm{GC}$, gas chromatograph

GC/MS, gas chromatography/mass spectrometry

$\mathrm{h}$, hour(s)

MDL, method detection limit

$\mu \mathrm{g} / \mathrm{L}$, microgram(s) per liter

$\mu \mathrm{L}$, microliter(s)

$\mu \mathrm{m}$, micrometer(s)

$\mathrm{mL}$, milliliter(s)

$\mathrm{mm}$, millimeter(s)

min, minute(s)

$\mathrm{ng} / \mathrm{L}$, nanogram(s) per liter

$\mathrm{ng} / \mu \mathrm{L}$, nanogram(s) per microliter(s)

s, second(s) 


\section{CONTENTS}

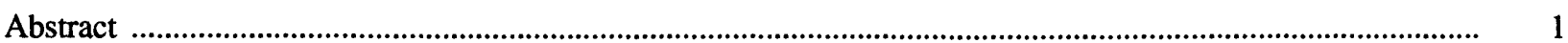

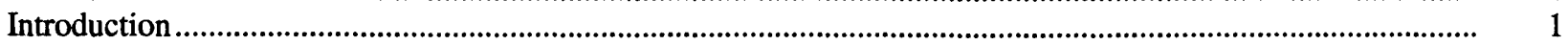

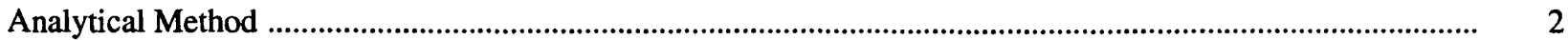

Scope and Application ................................................................................................................................... 2

Reagent Preparation .............................................................................................................................. 3

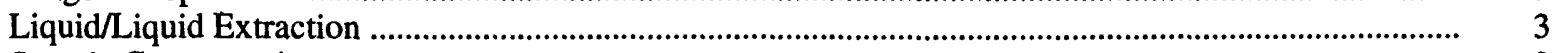

Sample Concentration ...............................................................................................................................

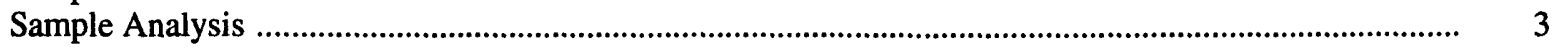

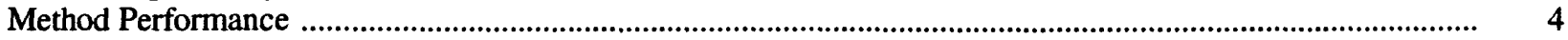

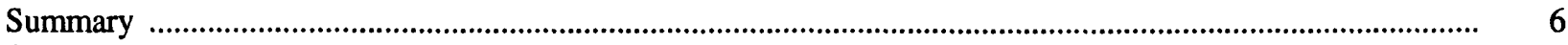

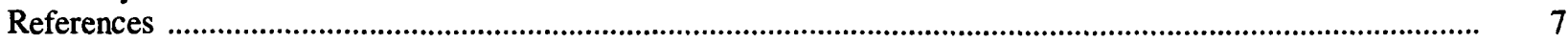

\section{FIGURES}

1. Diagram showing degradation pathway by which dibromochloropropane (DBCP) is transformed into the intermediate products dibromopropene (DBP) and bromochloropropene (BCP), then into the

final product, 2-bromoallyl alcohol (BAA) ...

2. Graph showing mass spectrum of 2-bromoallyl alcohol (BAA)

3. Graph showing mass spectrum of dibromopropene (DBP)

\section{TABLES}

1. Mean and standard deviation of recovery experiments for 2-bromoallyl alcohol and dibromopropene in three different matrices at two different concentration levels 


\title{
Determining Concentrations of 2-Bromoallyl Alcohol and Dibromopropene in Ground Water Using Quantitative Methods
}

\author{
by Sandra Y. Panshin
}

\section{Abstract}

A method for determining levels of 2-bromoallyl alcohol and 2,3-dibromopropene from ground-water samples using liquid/liquid extraction followed by gas chromatography/mass spectrometry is described. Analytes were extracted from the water using three aliquots of dichloromethane. The aliquots were combined and reduced in volume by rotary evaporation followed by evaporation using a nitrogen stream. The extracts were analyzed by capillary-column gas chromatography/mass spectrometry in the fullscan mode. Estimated method detection limits were 30 nanograms per liter for 2-bromoallyl alcohol and 10 nanograms per liter for 2,3-dibromopropene. Recoveries were determined by spiking three matrices at two concentration levels $(0.540$ and 5.40 micrograms per liter for 2-bromoallyl alcohol; and 0.534 and 5.34 micrograms per liter for dibromopropene). For seven replicates of each matrix at the high concentration level, the mean percent recoveries ranged from 43.9 to 64.9 percent for 2-bromoallyl alcohol, and from 87.5 to 99.3 percent for dibromopropene. At the low concentration level, the mean percent recoveries ranged from 43.8 to 95.2 percent for 2-bromoallyl alcohol, and from 71.3 to 84.9 percent for dibromopropene.

\section{INTRODUCTION}

The agricultural pesticide 1,2-dibromo-3chloropropane (DBCP) is a fumigant that was widely used on field crops, vegetables, fruits, and in greenhouses to kill nematodes. In the San Joaquin Valley, California, it was applied primarily to grapes and deciduous fruits planted in the sandy soils of the eastern part of the valley floor. In this region it was used from the late 1950s to 1977, when the California Department of Food and Agriculture banned its use because of its toxicity to humans. DBCP also was used for pineapple cultivation in Hawaii during a similar time period (Loague and others, 1989). The high solubility of DBCP, its relatively weak sorption properties, and its moderately long half-life have made it a persistent and mobile contaminant. There is extensive contamination of shallow ground water near Fresno, California, and in other parts of the United States from this pesticide.

Chemical degradation of DBCP in buffered aqueous solution was studied by Burlinson and others (1982), who suggested the pathway shown in figure 1. As a soluble, stable end-product, 2-bromoallyl alcohol (BAA) forms from either of two intermediates2-bromo-3-chloropropene (BCP) or 2,3-dibromopropene (DBP). The favored intermediate is BCP, which usually accounts for 95 percent of the haloalkene mass balance. Deeley and others (1991) conducted experiments in which they added DBCP to three different matrices: phosphate buffer solution; ground water from an aquifer near Fresno, California; and ground water/aquifer solid slurries also from the aquifer near Fresno, California. They were able to 
confirm the degradation pathway suggested by Burlinson and others (1982) when the reaction was carried out in phosphate buffer. They could not, however, confirm that BAA was the principal endproduct when they used the aquifer materials collected near Fresno, California. Instead, they found higher than expected concentrations of $\mathrm{BCP}$ and only trace levels of BAA, suggesting that another alcohol-glycerolwas a possible end-product. This suggestion is speculative, however, because the presence of glycerol was not determined analytically, but rather was calculated as the difference between the known input concentration of bromide in DBCP and the sum of the bromide concentrations in the analytically determined degradation products. They also suggested that there might have been analytical problems with the BAA analysis.

This report describes an analytical method for quantitatively determining the concentrations of BAA and DBP in ground-water samples from an area known to be contaminated with DBCP. If BAA is the final end-product of DBCP degradation, then determination of BAA and DBP in a water sample of known DBCP concentration would allow the estimation of in-situ DBCP half-life. This method also may be applicable for determining BCP; however, the unavailability of a $\mathrm{BCP}$ analytical standard in this study precluded documentation of the method's suitability for determination of this compound.
This method was developed by the California District Office of the U.S. Geological Survey for use as part of ground-water investigations in the National Water Quality Assessment Program (Dubrovsky, 1991). The method incorporates liquid/liquid extraction with dichloromethane for removal of the analytes from water samples and gas chromatography/ mass spectrometry operated in the full-scan mode for selective identification and quantitation of analytes. This report describes all aspects of the method, from sample preparation through calculation of results. Data on the precision and accuracy of the method, and estimated method detection limits for the analytes, also are presented.

\section{ANALYTICAL METHOD}

\section{Scope and Application}

This analytical method is applicable to the analysis of water samples containing BAA and DBP. $B A A$ is a degradation product of $D B C P$, and $D B P$ is an intermediate in this degradation process; therefore, this method is applicable to the analysis of water samples in areas of known or suspected DBCP usage.

Concentrations of BAA and DBP from the detection limits of 30 nanograms per liter (ng/L) and $10 \mathrm{ng} / \mathrm{L}$, respectively, to at least 5.4 micrograms per liter $(\mu \mathrm{g} / \mathrm{L})$<smiles>CC(O)(Br)C(Cl)CBr</smiles>

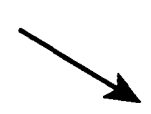<smiles>BrC=C(Br)CBr</smiles>

DBP<smiles>C=C(Br)CO</smiles><smiles>C=C(Br)CCl</smiles>

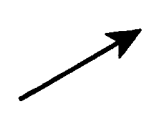

BAA<smiles>[B]</smiles>

Figure 1. Degradation pathway by which dibromochloropropane (DBCP) is transformed into the intermediate products dibromopropene (DBP) and bromochloropropene (BCP), then into the final product, 2-bromoallyl alcohol (BAA). 
can be quantitatively determined. No chemical interferences, that is, compounds with the same gas chromatographic retention times and masses as the analytes, were found.

\section{Reagent Preparation}

All glassware was thoroughly washed with soap and water, rinsed with organic-free water from a Picotech filtration system (Hydro Services and Supplies, Research Triangle Park, North Carolina), and heated to $450^{\circ} \mathrm{C}$ for 8 hours (h) prior to use. Teflon stopcocks were washed and rinsed using the same procedure, then air dried and rinsed with dichloromethane prior to use. All solvents were pesticideresidue grade. The internal standard, 3-bromo-3-buten1-ol, was purchased from Aldrich (Milwaukee, Wisconsin); a stock solution was made by mixing the pure liquid with methanol. Pure liquid DBP was purchased from Pfaltz and Bauer (Waterbury, Connecticut), and added to methanol to make a stock solution. The BAA standard was synthesized using a method described by Stearns and Deeley (written commun., 1993). This synthesis required dissolving 1 gram (g) of DBP in 200 milliliters (mL) of 0.01 molar sodium tetraborate $(\mathrm{pH} 9)$ and, stirring continuously while hydrolyzing the DBP for $20 \mathrm{~h}$ in an $85^{\circ} \mathrm{C}$ waterbath. The entire aqueous sample was extracted with $200 \mathrm{~mL}$ ethyl ether. The ether extract was dried over approximately $10 \mathrm{~g}$ anhydrous magnesium sulfate, then vacuum filtered. Ethyl ether was stripped from the sample by rotary evaporation followed by evaporation under a stream of nitrogen. This synthesis reaction had a yield of 80 to 100 percent and generated approximately $0.4 \mathrm{~mL}$ of BAA with a purity greater than 99 percent. The BAA was then dissolved in methanol to make a stock solution.

\section{Liquid/Liquid Extraction}

Approximately $500 \mathrm{~mL}$ of sample water was added to a clean, weighed bottle, which was then reweighed. The sample volume was then calculated. Enough sodium chloride (approximately $56 \mathrm{~g}$ ) was added to the sample to make a 10 percent (weight/ weight) $\mathrm{NaCl}$ solution, and the sample was shaken to dissolve all the salt. The sample then was placed in a separatory funnel and extracted with three $100 \mathrm{~mL}$ aliquots of pesticide-residue grade dichloromethane. For each aliquot, the funnel was shaken by hand for 5 minutes (min), the organic and aqueous phases were allowed to separate, and the organic layer was carefully removed without allowing any water into the collection flask. The three dichloromethane extracts then were combined.

\section{Sample Concentration}

The combined dichloromethane extract was reduced in volume to approximately $4 \mathrm{~mL}$ by rotary evaporation. The extract was transferred to a small amber vial, and the collection flask was rinsed twice with dichloromethane. Fifty microliters $(\mu \mathrm{L})$ of 15.2 nanograms per microliter $(\mathrm{ng} / \mu \mathrm{L})$ 3-bromo-3buten-1-ol was added to the extract as an internal standard. The volume of the extract was further reduced under a stream of nitrogen gas to approximately $200 \mu \mathrm{L}$. Extracts were stored at $-4^{\circ} \mathrm{C}$ until analysis.

\section{Sample Analysis}

Samples were analyzed using gas chromatography/mass spectrometry (GC/MS). The instrument consisted of a Varian capillary gas chromatograph (GC) connected to a Finnigan ion-trap detector. The GC was equipped with a DB-Wax column (J \& W Scientific, Folsom, California), which has a length of 15 meters (m), a film thickness of 0.5 micrometers $(\mu \mathrm{m})$, and an internal diameter of 0.25 millimeters $(\mathrm{mm})$. The sample was injected using splitless injection with the splitter turned on after 45 seconds (s). The GC temperature was held at $35^{\circ} \mathrm{C}$ for $1 \mathrm{~min}$, then increased to $180^{\circ} \mathrm{C}$ at a rate of $15^{\circ} \mathrm{C} / \mathrm{min}$ and held at $180^{\circ} \mathrm{C}$ for $2 \mathrm{~min}$. Mass spectra of the compounds were collected at a rate of 4-scans per second using the full-scan mode, which measured the abundance of all masses from 100 to 205-atomic mass units. The spectra of BAA and DBP are shown in figures 2 and 3 , respectively. GC retention times and appropriate masses for analysis for each compound (BAA, DBP, and 3-bromo-3-buten-1-ol) were determined by analyzing a standard of each compound separately. The approximate retention times were 5.85 min for DBP, 8.12 min for BAA, and 8.33-min for 3-bromo-3-buten-1-ol. Ions used for quantitation of DBP, BAA, and 3-bromo-3-buten-1-ol were 119, 119, and 122, respectively; confirmation ions for these compounds were 121,121 , and 120 , respectively.

Prior to each day's analyses, the GC/MS system was checked for the presence of air and water in the vacuum system, which, if present in large amounts, would indicate a leak and a poorly performing instrument. After the air and water check, the GC/MS operating parameters were optimized using the 


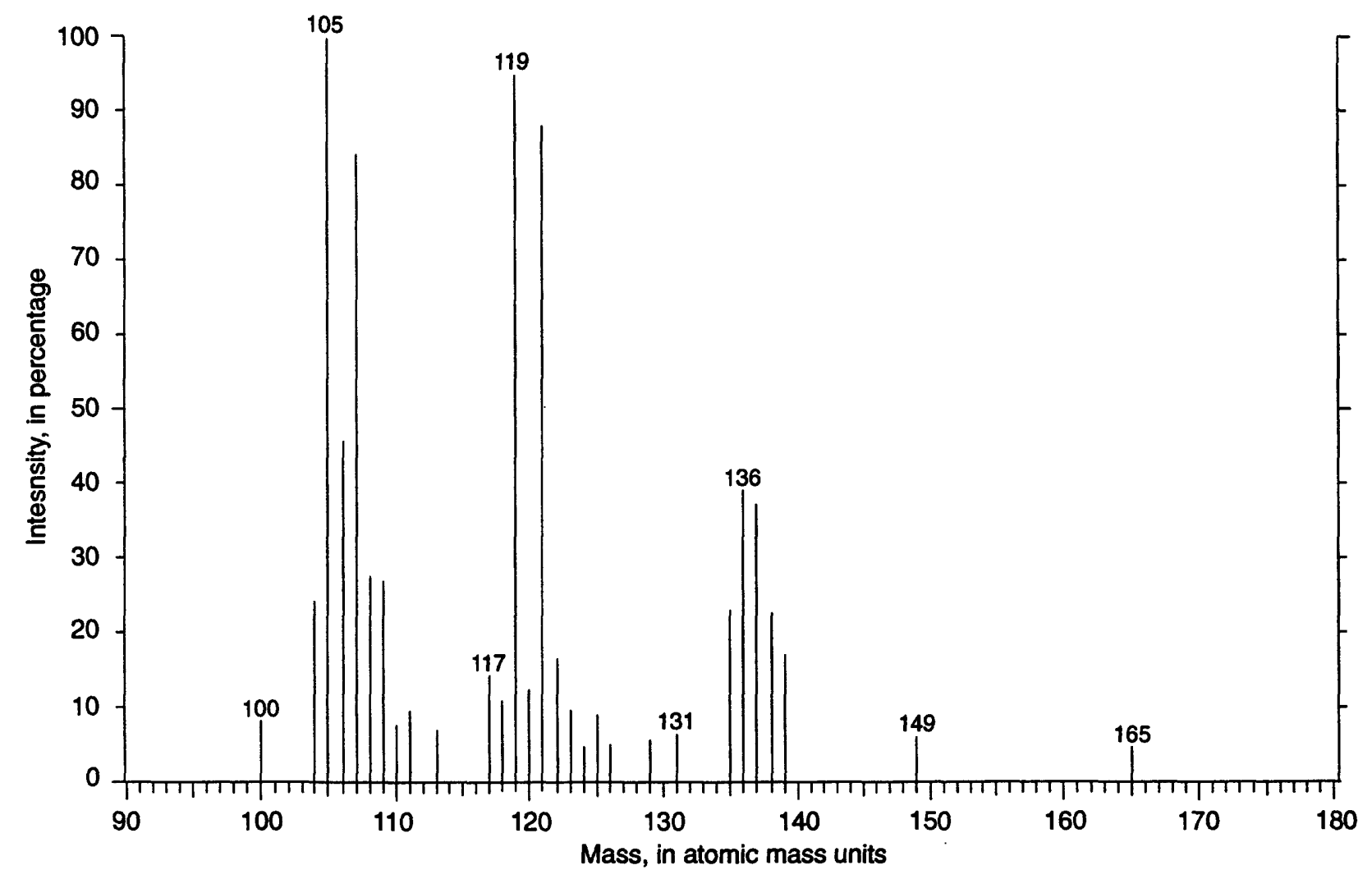

Figure 2. Mass spectrum of 2-bromoallyl alcohol (BAA).

standard autotune procedure from the Finnigan user's manual.

A set of standards was analyzed to evaluate the performance of the instrument each day before the samples were analyzed. Standards for both BAA and DBP ranged in concentration from $0.05 \mathrm{ng} / \mu \mathrm{L}$ to $2 \mathrm{ng} / \mu \mathrm{L}$ and had a 3-bromo-3-buten-1-ol concentration range of 3.35 to $3.70 \mathrm{ng} / \mu \mathrm{L}$. These standards allowed an estimation of the detection limits for BAA and DBP and an examination of the constancy of their response factors at different concentrations. The response factor is a measure of the sensitivity of the instrument to one compound relative to the internal standard, and is defined as

$$
R F=\left(A_{a} \times C_{i}\right) /\left(C_{a} \times A_{i}\right),
$$

where $R F=$ response factor, no dimension,

$A_{a}=$ peak area of the analyte quantitation ion,

$A_{i}=$ peak area of the internal standard quantitation ion,

$C_{a}=$ concentration of the analyte detected (in nanograms per microliter), and

$C_{i}=$ concentration of the internal standard injected (in nanograms per microliter).
The samples were analyzed after the standards. Positive identification of each analyte required that (1) the analyte have the same GC retention time as the standard compound and (2) both the quantitation ion and confirmation ion be present and have peak areas in the proper ratio.

\section{METHOD PERFORMANCE}

To test the method performance, ground-water samples were collected from two sites, Fresno, California, and Mililani, Hawaii. Unfortified organicfree water was used as a blank. Fortified samples of known concentration from the Fresno and Mililani wells, and fortified organic-free water, were used to determine the analyte recovery. Spiked samples were prepared at two different concentration levels. Seven replicates of each matrix (total of 21 samples) were fortified at the high-spike level of $5.34 \mu \mathrm{g} / \mathrm{L} \mathrm{DBP}$ and $5.40 \mu \mathrm{g} / \mathrm{L}$ BAA. Another seven replicates of each matrix (total of 21 samples) were fortified at the lowspike level of $0.534 \mu \mathrm{g} / \mathrm{L} \mathrm{DBP}$ and $0.540 \mu \mathrm{g} / \mathrm{L} \mathrm{BAA}$. The spike recovery is the percentage of analyte injected 


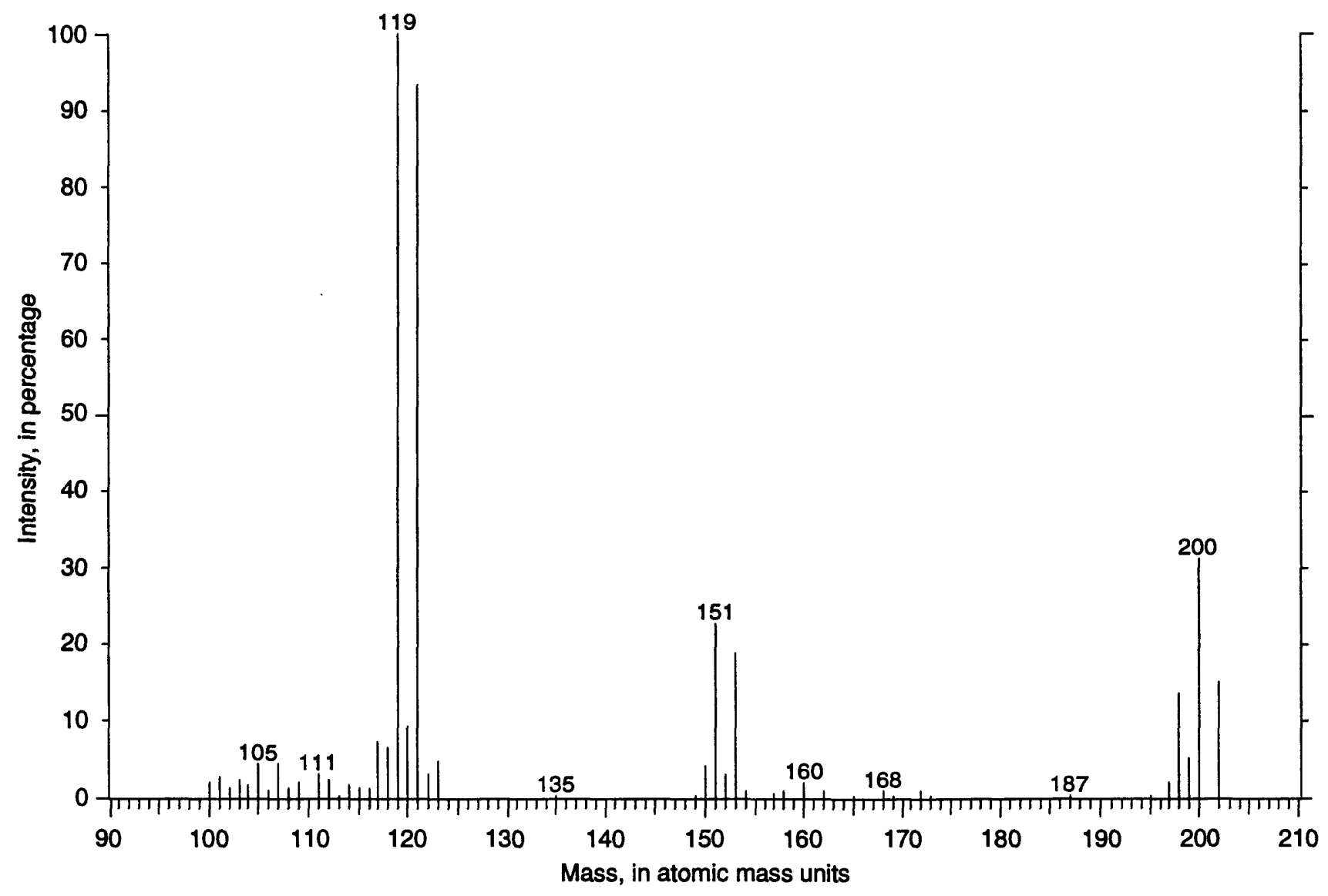

Figure 3. Mass spectrum of dibromopropene (DBP).

into the sample that is detected after the sample is processed and analyzed. To accurately calculate the spike recovery, a correction must be made for any analyte present in the sample that is not the result of the spiking solution. Therefore, an unspiked replicate must be analyzed in tandem with the spike to allow for this correction. The spike recovery can be calculated using equation 2:

$$
R=\left(C_{a s}-C_{u s}\right) \times 100 / C_{\text {Expected }},
$$

where

$R$ = percent recovery,

$C_{a s}=$ concentration of analyte in the spiked sample (in micrograms per liter),

$C_{u s}=$ concentration of analyte in the unspiked sample (in micrograms per liter), and

$C_{\text {Expected }}=$ concentration of analyte expected in the spiked sample (in micrograms per liter).

The values of $C_{a s}$ and $C_{u s}$ can be calculated using equation 3. $C_{a}$ in equation 3 will be either $C_{a s}$ or
$C_{u s}$, depending on whether the spiked or unspiked sample is being analyzed.

$$
C_{a}=\left(A_{a} \times C_{i}\right)\left(R F \times A_{i}\right),
$$

where $C_{a}, A_{a}, C_{i}, R F$, and $A_{i}$ are the same variables as defined in the discussion of response factors.

The value of $C_{\text {Expected }}$ can be calculated using equation 4:

$$
C_{\text {Expected }}=\left(C_{\text {Soln }} \times V_{\text {Soln }}\right)^{/ V_{S}},
$$

where

$C_{\text {Soln }}=$ concentration of the spiking solution injected into the sample (in micrograms per microliter),

$V_{\text {Soln }}=$ volume of the spiking solution injected into the sample (in microliters), and

$V_{S}=$ volume of the spiked sample (in liters).

Unfortified ground-water samples from these sites were analyzed to subtract out the indigenous concentrations to accurately calculate the recovery of 
Table 1. Mean and standard deviation of recovery experiments for 2-bromoallyl alcohol and dibromopropene in three different matrices at two different concentration levels

[Values for 2-bromoallyl alcohol (BAA): high $=5.40$ micrograms per liter $(\mu \mathrm{g} / \mathrm{L})$ and low $=0.540 \mu \mathrm{g} / \mathrm{L}$ and values for dibromopropene (DBP): high $=5.34 \mu \mathrm{g} / \mathrm{L}$ and low $=0.534 \mu \mathrm{g} / \mathrm{L}]$

\begin{tabular}{|c|c|c|c|c|}
\hline \multirow{2}{*}{$\begin{array}{c}\text { Spike } \\
\text { Designation }\end{array}$} & \multicolumn{2}{|c|}{ 2-Bromoallyl alcohol } & \multicolumn{2}{|c|}{ Dibromopropene } \\
\hline & $\begin{array}{c}\text { Mean Recovery } \\
\text { (percent) }\end{array}$ & Standard Deviation & $\begin{array}{l}\text { Mean Recovery } \\
\text { (percent) }\end{array}$ & Standard Deviation \\
\hline \multicolumn{5}{|l|}{ Organic-free } \\
\hline High & 66.0 & 3.4 & 99.3 & 12.9 \\
\hline Low & 95.2 & 29.6 & 84.0 & 24.4 \\
\hline \multicolumn{5}{|l|}{ San Joaquin } \\
\hline High & 43.9 & 4.3 & 91.9 & 11.9 \\
\hline Low & 49.7 & 15.9 & 84.9 & 22.5 \\
\hline \multicolumn{5}{|l|}{ Hawaii } \\
\hline High & 64.9 & 14.9 & 87.5 & 12.1 \\
\hline Low & 43.8 & 9.5 & 71.3 & 6.4 \\
\hline Overall & 60.6 & 23.3 & 86.5 & 17.5 \\
\hline
\end{tabular}

the spiked samples. Three replicates of unfortified water from each of the three matrices (Fresno ground water, Mililani ground water, and organic-free water, for a total of nine samples) were analyzed; neither BAA nor DBP was detected in any of these samples. Therefore, no correction was necessary for the tests reported here, because neither BAA nor DBP was detected in any of the unspiked samples.

Values of the mean percent recovery and standard deviation of the percent recovery for each of the six spike designations are shown in table 1 . The values of mean percent recovery for the six sets of spikes ranged from 43.8 to 95.2 percent for BAA, and from 71.3 to 99.3 percent for DBP. For seven replicates of each matrix at the high concentration level, the mean percent recoveries ranged from 43.9 to 64.9 percent for 2-bromoallyl alcohol, and from 87.5 to 99.3 percent for dibromopropene. At the low concentration level, the mean percent recoveries ranged from 43.8 to 95.2 percent for 2-bromoallyl alcohol, and from 71.3 to 84.9 percent for dibromopropene. Combining all the spikes into one data set resulted in a mean percent recovery of 60.6 percent for BAA and 86.5 percent for DBP.

The method detection limit (MDL) is the lowest concentration of analyte that can be detected and positively identified. It is defined as the concentration of analyte that gives a signal (peak area) three times higher than the standard deviation of the background noise in reagent water blanks (Skoog, 1985). The MDL for BAA is calculated at $30 \mathrm{ng} / \mathrm{L}$; and the MDL for DBP is $10 \mathrm{ng} / \mathrm{L}$. From the data presented, liquid/liquid extraction with dichloromethane followed by gas chromatography/mass spectrometry (GC/MS) is a precise and accurate method for analysis of BAA and $\mathrm{DBP}$ in ground water.

\section{SUMMARY}

This report describes the analytical method developed to determine the levels of two breakdown products of DBCP in ground water-BAA and DBP. The analytical method uses liquid/liquid extraction with dichloromethane and gas chromatography/mass spectrometry for analysis of these two compounds in water samples. The method was validated by using three matrices: organic-free water; Fresno, California ground water; and Mililani, Hawaii ground water. Each matrix was spiked at two concentration levels: the high level of $5.34 \mu \mathrm{g} / \mathrm{L}$ for DBP and $5.40 \mu \mathrm{g} / \mathrm{L}$ for BAA, and the low level of $0.534 \mu \mathrm{g} / \mathrm{L}$ for DBP and $0.540 \mu \mathrm{g} / \mathrm{L}$ for BAA. Recoveries ranged from 43.8 to 95.2 percent for BAA and from 71.3 to 99.3 percent for DBP. The MDL was $30 \mathrm{ng} / \mathrm{L}$ for BAA and $10 \mathrm{ng} / \mathrm{L}$ for $\mathrm{DBP}$. 


\section{REFERENCES}

Burlinson, N. E., Lee, L. A., Rosenblatt, D. H., 1982, Kinetics and products of hydrolysis of 1,2-dibromo-3chloropropane: Environmental Science and Technology, v. 16, p. 627-632.

Deeley, G. M., Reinhard, M., Stearns, S. M., 1991, Transformation and sorption of 1,2-dibromo-3chloropropane in subsurface samples collected at Fresno, California: Journal of Environmental Quality, v. 20, p. 547-556.
Dubrovsky, N. M., 1991, The National Water Quality Assessment Program-The San Joaquin - Tulare Basins: U.S. Geological Survey Open-File Report 91-153, 2 p.

Loague, K., Giambelluca, T. W., Green, R. E., Liu, C. C. K., Liang, T. C., Oki, D. S., 1989, Simulation of organic chemical movement in Hawaii soils with PRZM: 2. Predicting deep penetration of DBCP, EDB, and TCP: Pacific Science, v. 43, p. 362-383.

Skoog, D.A., 1985, Principles of Instrumental Analysis (3d ed.): Austin, Tex., Holt, Rinehart and Winston, 879 p. 